\title{
Variations in automatically recorded rumination time as explained by variations in intake of dietary fractions and milk production, and between-cow variation
}

\author{
M. V. Byskov, ${ }^{\dagger} \dagger^{1}$ E. Nadeau, $\ddagger$ B. E. O. Johansson, $\S$ and P. Nørgaard $\dagger$ \\ *Knowledge Centre for Agriculture-Cattle, 8200 Aarhus N, Denmark \\ †Department of Veterinary Clinical and Animal Sciences, Faculty of Health and Medical Sciences, University of Copenhagen, \\ 1870 Frederiksberg C, Denmark \\ †Department of Animal Environment and Health, Swedish University of Agricultural Sciences, 53223 Skara, Sweden \\ §Lantmännen, Bjertorps Egendom, 53591 Kvänum, Sweden
}

\begin{abstract}
Individual recording of rumination time (RT) is now possible in commercial dairy herds, through development of a microphone-based sensor, which is able to record RT by the sound of rumination activity. The objectives of this study were to examine the relationship between daily RT and intakes of different dietary fractions, the relationship between RT in minutes per kilogram of dry matter intake (DMI) and milk production, and to examine the variation in RT within and between mid-lactating dairy cows. Data from 3 production trials were used in which a total of 27 different diets were fed. The data contained 761, 290, and 203 daily recordings of RT, milk yield, milk components, DMI, and intake of dietary fractions recorded on 29, 26, and 24 Holstein and Swedish Red cows from trials 1, 2, and 3, respectively. The dietary fractions included forage neutral detergent fiber (NDF), concentrate NDF, crude protein, sugar, starch, and the remaining fraction represented by organic matter - (forage NDF + concentrate NDF + crude protein + sugar + starch). The relationship between the dietary fractions and RT was analyzed in 2 steps. In step 1, the dietary fractions, which were significantly related to RT, were selected and simultaneously checked for multicollinearity between the dietary components; in step 2, a multivariate model, including the effect of repeated measurements, the main effect of the selected dietary fractions from step 1, random effects of cow(trial) and trial, and information on breed, days in milk, and parity was used to analyze the relationship between RT and the selected dietary fractions. Relationships between RT in minutes per kilogram of DMI and milk yield and milk components were analyzed, using the same multivariate model as in step 2 . Approximately $32 \%$ of the variation in daily
\end{abstract}

Received February 3, 2014.

Accepted February 8, 2015.

${ }^{1}$ Corresponding author: mvl@vfl.dk
RT could be explained by variations in intakes of the dietary fractions, whereas $48 \%$ of the total variation in RT was accounted for by individual variations between cows. Intakes of forage NDF and starch were positively related to daily RT, whereas intakes of sugar and the remaining fraction were negatively related to daily RT. Rumination time in minutes per kilogram of DMI was negatively related to milk yield and protein percentage, but positively related to milk fat percentage.

Key words: dietary fraction, milk yield, rumination time

\section{INTRODUCTION}

Rumination activity is often recorded in intensive nutrition experiments studying the relationship between the intake of NDF from various feed types and rumen function expressed by rumination activity (Krause et al., 2002; Yang and Beauchemin, 2007). Mertens (1997) found that rumination activity is stimulated by the intake of physically effective fiber (peNDF) defined by a particle size greater than $1.18 \mathrm{~mm}$. Yang et al. (2001) found a correlation of 0.35 between total NDF intake and rumination time (RT). Furthermore, Yang and Beauchemin (2007) and Yang and Beauchemin (2009) found a correlation between the intake of forage NDF and RT of 0.41 and 0.44 , respectively. The latter of the 2 studies also found a correlation between forage peNDF and RT of 0.51. In the Nordic feed evaluation system, the rumination index value (min RT per $\mathrm{kg}$ of $\mathrm{DM}$ ) for a feed is predicted from the NDF content, particle size, and indigestible NDF/NDF ratio. Furthermore, concentrates with a particle size exceeding $2 \mathrm{~mm}$ are considered to stimulate RT (Nørgaard et al., 2011). Nørgaard et al. (2010) found that the mean rumination time was 109 and 88 min per $\mathrm{kg}$ of forage NDF intake for grass silage and alfalfa hay, respectively, when data were adjusted to a standard cow with a BW of $625 \mathrm{~kg}$, DMI of $20 \mathrm{~kg}$ per d, and a forage NDF intake of $0.7 \%$ of BW. Although the intake of peNDF is considered to 
stimulate RT, high intakes of easily fermentable carbohydrates may indirectly result in decreased RT through a higher concentrate intake, because usually a lower content of peNDF is present in concentrate compared with forage. However, other factors such as breed, size (Bae et al., 1983), and parity (Beauchemin and Rode, 1994) have also been shown to affect rumination activity. In addition, high energy density and low peNDF content have been related to a high milk yield, low milk fat yield, and low RT (Teimouri Yansari et al., 2004; Adin et al., 2009). Recently, a rumination monitoring system (RMS; RuminAct-Milkline, Gariga di Podenzano, Italy), recording RT by the sound pattern of regurgitation and rhythmic jaw movements during rumination activity, has enabled RT of individual cows in commercial dairy herds to be recorded. The RMS is found to record rumination activity with reasonable accuracy (Schirmann et al., 2009; Byskov et al., 2014). Recent research, which has recorded RT by the RMS on 32 transition Holstein cows, has shown that some of the variation in RT between cows was associated with health status (Soriani et al., 2012). In relation to this, the collection of large amounts of data on RT, enabled by the RMS, provides an opportunity to study variations within and between healthy cows while accounting for variations in dietary intake, which to the authors' knowledge has not yet been performed using a large amount of data. Furthermore, this type of data makes it possible to analyze how the variation in intake of different dietary fractions and milk production can be related to daily recorded RT values on an individual cow basis. Therefore, the objective was to study the relationship between daily RT recorded by RMS and intakes of different dietary fractions and milk production in Swedish Red and Holstein cows. In addition, the objective was to determine variations in RT within and between cows, while accounting for variations in intake of the dietary fractions.

\section{MATERIALS AND METHODS}

\section{Trials, Diets, and Experimental Design}

Data from 3 experimental trials with lactating dairy cows were used in this study. The experimental design of trial 1 was a 3 -factor Box-Behnken design with 3 levels of crushed linseed supplementation, 3 levels of forage, and 3 levels of a grass/corn silage mix. Thirteen different diets were fed, where the crushed linseed supplementations were 1,3 , and $5 \%$ of DM; the forage proportions were 35,50 , and $65 \%$ of DM; and the grass/ corn silage proportions were 20,50 , and $80 \%$ of DM. Diet 13 (3\% crushed linseed, 50\% forage proportion, and $50 \%$ grass/corn silage proportion of DM) was con- sidered the center point treatment in the Box-Behnken design. The trial was conducted over 4 periods of 21 d, feeding 4 different diets to 4 groups of cows in each period, with the center point treatment (diet 13) fed in each period. Cows were blocked into the 4 groups according to breed, parity, and milk yield. For further details, see Sterk et al. (2011).

The experimental design of trial 2 was also a 3 -factor Box-Behnken with 3 concentrations of soluble carbohydrates without sugar, 3 concentrations of starch, and 3 concentrations of sugar. As in the previous trial, 13 different diets were fed, varying the soluble carbohydrates without sugar concentration between 100, 140, and 170 $\mathrm{g} / \mathrm{kg}$ of DM; the concentration of starch between 110 , 150 , and $200 \mathrm{~g} / \mathrm{kg}$ of $\mathrm{DM}$; and the concentration of sugar between 17 and $52 \mathrm{~g} / \mathrm{kg}$ of DM. The trial was conducted according to the same principles as for trial 1 , with 4 groups of cows fed 4 different diets in 21-d periods. Yet again, diet 13 was considered the center point treatment.

The experimental design of trial 3 was a duplicated $3 \times 3$ Latin square design with 3 periods and 3 treatments with 12 cows per treatment per period. Each cow received each treatment for a period of $20 \mathrm{~d}$. The treatments included 2 types of silage additives (Kofasil Life containing Lactobacillus plantarum DSM 3676, 3677, 400,000 cfu/g and Kofasil Ultra K containing $16.5 \%$ sodium nitrite, $11.0 \%$ hexamethylene tetramine, $8.1 \%$ potassium sorbate, $2.2 \%$ sodium benzoate, $0.8 \%$ sodium propionate at $2 \mathrm{~L} / \mathrm{t}$; ADDCON Europe $\mathrm{GmbH}$, Bonn, Germany) and untreated control grass silage. The silage, which consisted of $77 \%$ grass, $18 \%$ clover, and $5 \%$ alfalfa, was harvested from the same field on June 3, 2010. The silage treatment was mixed with a concentrate before being fed to the cows. For all 3 trials, all recorded data during adaptation and experimentation periods for DMI, RT, milk yield, and milk components were included. The silages fed in all 3 trials were chopped to approximately the same theoretical length of cut.

\section{Housing, Recordings, and Cows}

All 3 trials were approved and conducted under the Swedish Law on Animal Experimentation. The trials were conducted in an experimental production herd (Nötcenter Viken, Lantmännen, Sweden). The cows were housed in a free stall barn with slatted floors and cubicles with rubber mats bedded with sawdust. Milk yield, feed intake, and RT were recorded daily for individual cows during the experimental periods. Cows had ad libitum access to feed via automatic feed bins (BioControl A/S, Rakkestad, Norway), continuously weighing the residuals to determine individual 
feed intake. Access to the feed bins and recording of individual feed intake was enabled by a transponder fitted to each cow. The experimental diets were fed as TMR and delivered once daily at approximately 0900 $\mathrm{h}$. Water was provided with free access at all times. Cows were milked 3 times daily at 0600, 1300, and $2100 \mathrm{~h}$ in all trials. Individual daily RT was recorded by the RMS by a sensor placed dorsally on the left side of the neck. Data from these sensors were collected by an antenna placed in the milking parlor and processed by the provided software. Rumination time was displayed as time spent ruminating per 24-h interval starting from midnight. However, because the recording of RT was not the original purpose of these trials, RT recording was only performed on some of the cows within each trial. Individual live weights $(\mathbf{L W})$ were recorded 3 times daily on exit from the milking parlor for 2 consecutive days, at initiation and termination of each period in trial 3 . In trial 2,3 daily recordings of LW were performed on the same $3 \mathrm{~d}$ as milk sampling. No LW recording was performed in trial 1.

\section{Sampling Procedures and Analyses}

Milk samples to determine fat, protein, lactose, and SCC in milk were drawn from 9 consecutive milkings during the last $3 \mathrm{~d}$ of each experimental period for all trials. The samples were pooled from each sample-day in equal quantities and stored at $4^{\circ} \mathrm{C}$ preserved with sodium azide bronopol. Fat, protein, lactose percentages, and SCC were determined by the Steins Laboratory (Jönkoping, Sweden) using a Milkoscan FT 6000 (A/S N, Foss Electric, Hillerød, Denmark). Forage feeds were sampled daily during the last 7,5 , and $7 \mathrm{~d}$ of each trial period for trial 1, 2, and 3, respectively. Concentrates were sampled once for each trial period for trials 2 and 3 and simultaneously with forage feed samples for trial 1. In trial 1, the DM content of feed samples was determined by oven-drying at $103^{\circ} \mathrm{C}$ for $24 \mathrm{~h}$, whereas ash content was determined by combusting the feed at $550^{\circ} \mathrm{C}$. Neutral detergent fiber was determined according to Van Soest et al. (1991), modified by addition of $\alpha$-amylase and sodium sulfite. Crude protein content was determined by the Kjeldahl method using $\mathrm{CuSO}_{4}$ as a catalyst. Sugar content was determined by using a $40 \%$ ethanol solution as described by van Vuuren et al. (1993), and starch content was determined by enzymatic hydrolysis. In trial 2, silage DM content was determined by oven-drying at $60^{\circ} \mathrm{C}$ until constant weight. Neutral detergent fiber, CP, and sugar contents were determined by near-infrared spectroscopy, whereas starch content was determined by dissolving in ethanol. For the concentrates fed in trial 2, ash content was determined by combustion at $550^{\circ} \mathrm{C}$, NDF content was determined by Van Soest et al. (1991) modified by addition of $\alpha$-amylase. Crude protein content was determined by the Kjeldahl method; sugar content was determined by first extracting with water and then with hydrochloric acid; and starch content was determined by the same methods as for the silages. For trial 3, silage $\mathrm{DM}$ was determined by oven-drying at $60^{\circ} \mathrm{C}$ until a constant weight. For concentrates, DM was determined by oven-drying at $105^{\circ} \mathrm{C}$ for $24 \mathrm{~h}$, whereas DM of the TMR was determined by oven-drying at $60^{\circ} \mathrm{C}$ for $24 \mathrm{~h}$. The in vitro digestibility of the OM of silage was analyzed according to Lindgren (1979) and the ME value was calculated from the in vitro digestibility of OM according to Lindgren (1983). The NDF was analyzed according to Van Soest et al. (1991), modified by addition of $\alpha$-amylase. Starch content was analyzed in the concentrate by an enzymatic method according to Aman and Hesselman (1984). Water-soluble carbohydrates of the silage were analyzed according to von Lengerken and Zimmermann (1991).

\section{Feeds and Dietary Fractions}

The composition and feed types varied greatly both within and between the 3 trials, with the sole common feed between the diets being grass silage (Table 1). In trials 1 and 2 , the forage proportion varied between 35 and $65 \%$ and between 30 and $48 \%$ of total DM, respectively. The forage proportion for trial 3 was $51 \%$ of $\mathrm{DM}$ for all 3 treatments. Within the 3 trials, the chemical composition of the diets was classified into 6 dietary fractions, altogether constituting the OM of each diet. The 6 dietary fractions of the TMR diets were forage NDF, concentrate NDF, CP, starch, sugar, and the remaining fraction equal to $\mathrm{OM}-$ (forage NDF + concentrate NDF + CP + starch + sugar). These dietary fractions were chosen based on their hypothesized effect on RT. The content of the dietary fractions from each diet is shown in Tables 2, 3, and 4 .

\section{Data Preparation}

Individual daily feed intake was estimated as the sum of TMR intake recorded by the automatic feed bins during each day. The TMR intake was converted to DMI using the specific DM content for each dietary treatment and period. The data consisted of daily recordings of RT, milk yield, milk components, DMI, and intake of dietary fractions. Data on unrealistically high or low DMI outside the range of 75 to $120 \%$ of expected DMI were removed. Unrealistically high or low DMI was expected due to the stealing of feed between cows. The expected DMI was calculated using the formula: expected $\mathrm{DMI}=0.43 \times$ milk yield +5.7 (Lindgren et al., 
Table 1. Diet composition and variation in each of the 3 trials

\begin{tabular}{|c|c|c|c|}
\hline & Trial 1 & Trial 2 & Trial 3 \\
\hline Feed, $\mathrm{g} / \mathrm{kg}$ of DM & Mean $\pm \mathrm{SD}$ & Mean \pm SD & Mean $^{1}$ \\
\hline Grass silage & $250.0 \pm 139.4$ & $290.4 \pm 88.3$ & 514.1 \\
\hline Corn silage & $250.0 \pm 139.4$ & $119.4 \pm 101.6$ & - \\
\hline Alfalfa hay & - & $67.9 \pm 79.2$ & - \\
\hline Crushed linseed & $30.0 \pm 16.3$ & & - \\
\hline Sprouted barley, malt & - & $21.4 \pm 35.2$ & - \\
\hline Barley, ground & - & - & 143.3 \\
\hline Wheat, ground & $101.9 \pm 33.5$ & $55.9 \pm 39.4$ & 54.7 \\
\hline Oats, ground & $92.8 \pm 30.8$ & & - \\
\hline Rapeseed meal, heat treated & $66.9 \pm 24.7$ & & - \\
\hline Soybean meal & $38.5 \pm 18.7$ & $78.2 \pm 37.7$ & - \\
\hline SoyPass & $44.7 \pm 7.0$ & & 42.3 \\
\hline Soya hulls & - & $15.7 \pm 17.6$ & - \\
\hline Sugar beet pulp & $39.2 \pm 19.3$ & $43.3 \pm 59.8$ & - \\
\hline Sugar beet pulp fiber & - & $30.3 \pm 50.0$ & - \\
\hline Heat-treated canola & - & - & 16.1 \\
\hline Potato protein & - & - & 13.1 \\
\hline Citrus pulp & - & $14.3 \pm 26.0$ & - \\
\hline Rapeseed meal & $21.0 \pm 10.2$ & $38.9 \pm 41.3$ & - \\
\hline Rapeseed, crushed & $2.8 \pm 1.2$ & $16.8 \pm 25.7$ & - \\
\hline Wheat bran & - & - & 37.6 \\
\hline Oat bran meal & $12.1 \pm 9.5$ & $23.4 \pm 26.0$ & - \\
\hline Wheat bran meal & $3.3 \pm 3.9$ & $39.3 \pm 54.8$ & 41.1 \\
\hline Triticale, ground & $2.6 \pm 3.1$ & $40.1 \pm 45.2$ & - \\
\hline Corn, grain & - & $21.5 \pm 31.3$ & 22.8 \\
\hline Palm expeller & $4.2 \pm 1.3$ & & 72.1 \\
\hline Rice meal & - & $8.3 \pm 16.3$ & - \\
\hline Sorghum & - & $11.9 \pm 18.0$ & - \\
\hline Molasses & - & $18.4 \pm 29.1$ & - \\
\hline Dried distillers grain plus solubles & $5.5 \pm 1.6$ & $25.1 \pm 20.8$ & - \\
\hline Sugar by-product & - & $4.0 \pm 10.0$ & - \\
\hline Limestone & - & - & 5.1 \\
\hline $\mathrm{MgO}$ & - & - & 1.4 \\
\hline Fat & - & - & 14.1 \\
\hline Zinc & - & $8.8 \pm 10.0$ & - \\
\hline Other & $33.2 \pm 10.7$ & - & 19.3 \\
\hline Premix & $1.0 \pm 0$ & - & 0.9 \\
\hline
\end{tabular}

${ }^{1}$ No SD provided. The diet composition was formulated to be the same for all 3 diets.

2001). Furthermore, data without recordings on milk yield, feed intake, and RT were also removed. Finally, extreme data on RT and DMI, below 100 min and 5 $\mathrm{kg}$ of $\mathrm{DM} / \mathrm{d}$, respectively, were excluded. For all trials, most of the data removed was due to a lack of RT data because RT recording was not the original purpose of the 3 trials. For trial 1, the editing procedures removed 2,944 daily recordings. The remaining data for trial 1

Table 2. Number of recordings, number of cows, and nutrient contents of diets in trial 1

\begin{tabular}{|c|c|c|c|c|c|c|c|c|c|c|c|c|c|}
\hline \multirow[b]{2}{*}{ Item } & \multicolumn{13}{|c|}{ Diet no. } \\
\hline & 1 & 2 & 3 & 4 & 5 & 6 & 7 & 8 & 9 & 10 & 11 & 12 & 13 \\
\hline $\mathrm{DM}$ of TMR, $\mathrm{g} / \mathrm{kg}$ & 373 & 356 & 504 & 518 & 428 & 389 & 425 & 412 & 352 & 474 & 344 & 510 & 400 \\
\hline \multicolumn{14}{|l|}{ Content, $\mathrm{g} / \mathrm{kg}$ of $\mathrm{DM}$} \\
\hline Forage NDF & 319 & 317 & 172 & 171 & 245 & 244 & 244 & 244 & 318 & 171 & 318 & 171 & 245 \\
\hline Starch & 155 & 117 & 209 & 189 & 187 & 154 & 184 & 151 & 151 & 204 & 134 & 197 & 170 \\
\hline Sugar & 44 & 38 & 53 & 50 & 50 & 37 & 49 & 44 & 41 & 43 & 36 & 51 & 46 \\
\hline Remaining fraction ${ }^{1}$ & 193 & 219 & 193 & 187 & 187 & 210 & 186 & 219 & 195 & 194 & 134 & 190 & 196 \\
\hline
\end{tabular}

${ }^{1}$ Remaining fraction $=\mathrm{OM}-($ forage NDF + concentrate NDF $+\mathrm{CP}+$ starch + sugar $)$. 
Table 3. Number of recordings, number of cows, and nutrient contents of diets in trial 2

\begin{tabular}{|c|c|c|c|c|c|c|c|c|c|c|c|c|c|}
\hline Item & \multicolumn{13}{|c|}{ Diet no. } \\
\hline No. of recordings per diet & 4 & 43 & 8 & 13 & 39 & 55 & 20 & 3 & 6 & 6 & 16 & 8 & 76 \\
\hline $\mathrm{DM}$ of TMR, $\mathrm{g} / \mathrm{kg}$ & 392 & 426 & 578 & 504 & 410 & 471 & 416 & 483 & 462 & 472 & 504 & 456 & 438 \\
\hline \multicolumn{14}{|l|}{ Content, $\mathrm{g} / \mathrm{kg}$ of DM } \\
\hline Forage NDF & 216 & 264 & 154 & 173 & 138 & 246 & 189 & 203 & 168 & 178 & 171 & 232 & 213 \\
\hline Sugar & 40 & 39 & 49 & 52 & 24 & 17 & 70 & 80 & 28 & 36 & 83 & 65 & 41 \\
\hline Remaining fraction $^{1}$ & 195 & 218 & 179 & 232 & 174 & 228 & 186 & 248 & 212 & 199 & 192 & 190 & 202 \\
\hline
\end{tabular}

${ }^{1}$ Remaining fraction $=\mathrm{OM}-($ forage $\mathrm{NDF}+$ concentrate $\mathrm{NDF}+\mathrm{CP}+$ starch + sugar $)$.

consisted of 761 daily recordings from 11 Holstein cows and 18 Swedish Red mid-lactating cows with a mean parity of $2.5 \pm 1.4$ and $119 \pm 6.2$ DIM. For trial 2, data editing procedures removed 3,081 daily recordings, with the majority removed due to a lack of RT data. The remaining data for trial 2 consisted of 290 daily recordings from 13 Holstein cows and 13 Swedish Red mid-lactating cows with a mean parity of $2.3 \pm 0.5$ and $133 \pm 6.3$ DIM. For trial 3, data editing procedures removed 575 recordings. The remaining data for trial 3 consisted of 203 daily recordings from 10 Holstein and 14 Swedish Red mid-lactating cows with a mean parity of $2.4 \pm 0.8$ and $107 \pm 6.9$ DIM. The editing procedure, removing a large part of the data, created unbalanced data. To account for each diet to be represented by recording of at least 2 cows, data from diets 1 and 8 from trial 2 were deleted (Table 3 ).

Individual LW for cows in all trials was predicted based on information from a model developed on LW data from trials 2 and 3, with information on DIM, parity and breed (Table 5). For the prediction of LW, parity was divided into 2 groups of cows with parities $\leq 2$ (parity group 1 ) and cows with parities $\geq 3$ (par-

Table 4. Number of recordings, number of cows, and nutrient contents of diets in trial 3

\begin{tabular}{lrrl}
\hline Diet no. & 1 & \multicolumn{1}{c}{2} & \multicolumn{1}{c}{3} \\
\hline No. of recordings per diet & 58 & 69 & 76 \\
No. of cows per diet & 19 & 18 & 19 \\
DM of TMR, g/kg & 486 & 533 & 525 \\
Content, g/kg of DM & & & \\
Forage NDF & 208 & 206 & 209 \\
Concentrate NDF & 147 & 148 & 148 \\
CP & 174 & 175 & 171 \\
Starch & 157 & 157 & 157 \\
Sugar & 91 & 90 & 118 \\
Remaining fraction $^{1}$ & 152 & 154 & 127 \\
\hline
\end{tabular}

${ }^{1}$ Remaining fraction $=\mathrm{OM}-($ forage $\mathrm{NDF}+$ concentrate $\mathrm{NDF}+\mathrm{CP}$ + starch + sugar). ity group 2). To characterize the general size of each cow, weight was estimated as the mean of the daily predicted LW at initiation and termination of each trial $(\mathbf{m p L W})$. The daily yield of ECM was estimated from the percentage of fat, protein, and lactose according to Sjaunja et al. (1990).

\section{Statistical Analysis}

All statistical analyses were performed in SAS 9.2 (SAS Institute Inc., Cary, NC). Predictions of individual LW for cows in all trials were performed using the MIXED procedure based on data from trials 2 and 3 in accordance with the model:

$$
\begin{gathered}
\mathrm{Y}_{\mathrm{i}}=\mu+\mathrm{a}\left(\text { parity group }_{\mathrm{i}}\right)+\mathrm{b}\left(\text { breed }_{\mathrm{i}}\right)+\mathrm{c}\left(\mathrm{DIM}_{\mathrm{i}}\right) \\
+\mathrm{d}\left(\text { parity }_{\operatorname{group}} \times \mathrm{DIM}_{\mathrm{i}}\right)+\mathrm{A}\left[\operatorname{cow}\left(\text { trial }_{\mathrm{i}}\right]\right. \\
+\mathrm{B}\left(\text { trial }_{\mathrm{i}}\right)+e_{\mathrm{i}},
\end{gathered}
$$

where $Y_{i}$ is the dependent variable, $\mu$ is the overall mean, a (parity group $_{\mathrm{i}}$ ) is the fixed effect of parity group, $b\left(\right.$ breed $\left._{i}\right)$ is the fixed effect of breed, $c\left(D I M_{i}\right)$ is

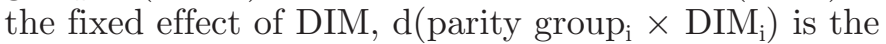
interaction between parity group and DIM, A[cow(trial) i] is the random effect of cow (trial), B $\left(\right.$ trial $\left._{\mathrm{i}}\right)$ is the random effect of trial, and $e_{\mathrm{i}}$ is the error term.

The selection of parameters included in the final models was managed in 2 steps. In step 1, the selection of the parameters was performed considering only the main effects of the dietary fractions, breed, parity, and DIM in the REG procedure in SAS 9.2, using daily RT as a response. The main effects were selected based on stepwise reduction with $P>0.15$. Multicollinearity between the entering variables was evaluated using the variance inflation factor and tolerance, excluding main effects with a variation inflation factor $>10$ and tolerance $<0.1$. 
Table 5. Relationships between mean predicted live weight and breed, parity group, and DIM

\begin{tabular}{|c|c|c|c|c|c|}
\hline Regression factor & Estimate & SEM & $P$-value & $\mathrm{R}_{\mathrm{RA}}^{2}$ & $\mathrm{R}_{\mathrm{WRA}}^{2}$ \\
\hline & & & & 0.96 & 0.48 \\
\hline Intercept & 547 & 18.3 & - & & \\
\hline Breed: Holstein & 30.0 & 13.7 & $<0.05$ & & \\
\hline Breed: Swedish Red & 0 & - & - & & \\
\hline Parity group $1^{3}$ & 23.7 & 19.5 & 0.20 & & \\
\hline Parity group $2^{4}$ & 0 & - & - & & \\
\hline DIM & 0.71 & 0.09 & $<0.001$ & & \\
\hline DIM $\times$ parity group 1 & -0.52 & 0.11 & $<0.001$ & & \\
\hline $\mathrm{DIM} \times$ parity group 2 & 0 & - & - & & \\
\hline
\end{tabular}

In step 2, the selected main effects forage NDF, sugar, starch, and the remaining fraction from step 1 were fitted to 2 multivariate mixed models, one including the intake variables in kilograms per day and one including the same intake variables expressed in a percentage of mpLW with random effects of cow(trial) and trial with the MIXED procedure. The effects of breed, parity, and DIM of the cows were included in both models. To account for the potential serial correlation structure of the repeated measurements within each cow(trial), the exponential, Gaussian, or first-order autoregressive decrease of the variance-covariance structure of the repeated measurements was implemented into the model. The variance-covariance structure of the repeated measurements was evaluated and selected based on the smallest Bayesian information criterion. The effects were excluded from the 2 multivariate mixed models by backward elimination procedure at $P \geq 0.05$. The goodness of fit for the 2 models was evaluated by the root mean square error, calculated as the square root of the residual variance. The percentage of total variation explained by the dietary fractions was estimated as the $\mathrm{R}^{2}$ between the observed and predicted RT, with and without the random effects of cow(trial) and trial.

Relationships between RT in minutes per kilogram of DMI and milk yield, percentages of fat, protein, and lactose, and SCC in milk and cow characteristics described by breed, parity, mpLW, and DIM were analyzed using a multivariate mixed model, in accordance with the same principles described by the previous step 2. However, information on milk yield and milk component percentages was used instead of intake of the dietary components. The analyses, using daily RT for dietary fractions and daily RT in minutes per kilogram of DMI for milk production as response variables, were performed using the following overall model:

$$
\mathrm{Y}_{\mathrm{i}}=\mathbf{X} \alpha_{\mathrm{i}}+\mathbf{Z} \beta_{\mathrm{i}}+\delta_{\mathrm{i}}+\varepsilon_{\mathrm{i}}
$$

where $Y_{i}$ is the response variable and $\mathbf{X}$ is a vector of regression coefficients for the selected fixed variables represented by $\alpha_{i}$. The random effects are represented by the vector $\mathbf{Z}$ with regression coefficients for the random effects of cow $(\text { trial })_{i}$ and trial ${ }_{i}$, represented by $\beta_{\mathrm{i}}$. The $\delta_{\mathrm{i}}$ represents the correlation structure between measurements over time (DIM) on each cow(trial) and trial, and $\varepsilon_{\mathrm{i}}$ represents the random residual error, which is assumed to be normally distributed with a mean of 0 and a constant variance. Determination of the variation in RT within and between cows was accounted for by the variance components. Partial Pearson correlation coefficients between the dietary fractions and between RT and forage NDF were determined by the CORR procedure, using the PARTIAL statement to state the partial effects.

\section{RESULTS}

\section{Prediction of Live Weight}

The mpLW was higher for Holstein cows compared with Swedish Red cows and increased with increasing DIM (Table 5). However, this increase was smaller for cows with parity $\leq 2$ than for cows with parity $\geq 3$. Almost one-half of the variation was due to a variation in the random effects of cow(trial) and trial, with $\mathrm{R}^{2}$ values of 0.96 and 0.48 with and without the random effects respectively.

\section{Relationships Between Rumination Time and Dietary Fractions}

Data for the regression analyses are shown in Table 6. The preliminary selection of parameters by step 1 in the statistical analysis, considering the relation between RT and intake in kilograms per day or intake as a percentage of mpLW of dietary fractions, identified for- 
Table 6. Mean, minimum, maximum, and standard deviation of variables used in the regression analyses

\begin{tabular}{|c|c|c|c|c|}
\hline Item & Mean & Minimum & Maximum & $\mathrm{SD}$ \\
\hline \multicolumn{5}{|l|}{ Parameter } \\
\hline Parity & 2.3 & 1 & 4 & 0.9 \\
\hline DIM & 122.7 & 36 & 241 & 34.9 \\
\hline $\mathrm{mpLW},{ }^{1} \mathrm{~kg}$ & 617.6 & 525.1 & 764.5 & 33.9 \\
\hline DMI, $\mathrm{kg} / \mathrm{d}$ & 22.8 & 13.0 & 35.5 & 3.8 \\
\hline $\mathrm{RT},{ }^{2} \min / \mathrm{d}$ & 470 & 200 & 744 & 118 \\
\hline $\mathrm{RT}, \mathrm{min} / \mathrm{kg}$ of $\mathrm{DMI}$ & 21.2 & 7.3 & 42.1 & 6.3 \\
\hline Milk yield, $\mathrm{kg} / \mathrm{d}$ & 40.9 & 20.4 & 64.6 & 6.9 \\
\hline $\mathrm{ECM}, \mathrm{kg} / \mathrm{d}$ & 39.9 & 19.8 & 59.4 & 6.6 \\
\hline Fat, $\%$ & 3.9 & 2.3 & 5.7 & 0.6 \\
\hline Protein, \% & 3.2 & 2.1 & 4.0 & 0.3 \\
\hline Lactose, $\%$ & 4.8 & 3.2 & 6.2 & 0.2 \\
\hline SCC, 1,000 cells/mL & 92.6 & 4.0 & $1,458.0$ & 149.4 \\
\hline \multicolumn{5}{|l|}{ Intake, $\mathrm{kg} / \mathrm{d}$} \\
\hline Forage NDF & 5.3 & 2.1 & 10.0 & 1.3 \\
\hline Concentrate NDF & 2.7 & 0.7 & 6.6 & 1.1 \\
\hline $\mathrm{CP}$ & 4.2 & 2.3 & 6.6 & 0.7 \\
\hline Sugar & 1.2 & 0.3 & 3.4 & 0.6 \\
\hline Starch & 3.7 & 1.7 & 7.1 & 1.0 \\
\hline Remaining fraction ${ }^{3}$ & 4.4 & 1.9 & 7.0 & 0.9 \\
\hline \multicolumn{5}{|l|}{ Intake, ${ }^{1} \%$ of mpLW } \\
\hline Forage NDF & 0.85 & 0.31 & 1.60 & 0.21 \\
\hline Concentrate NDF & 0.44 & 0.11 & 1.01 & 0.17 \\
\hline $\mathrm{CP}$ & 0.67 & 0.36 & 1.07 & 0.12 \\
\hline Sugar & 0.19 & 0.04 & 0.62 & 0.09 \\
\hline Starch & 0.60 & 0.28 & 1.13 & 0.15 \\
\hline Remaining fraction $^{3}$ & 0.71 & 0.29 & 1.15 & 0.15 \\
\hline
\end{tabular}

${ }^{1}$ For all trials LW was predicted based on a mixed model including information on breed, DIM, and parity. Based on that, mean predicted live weight (mpLW) was calculated as the mean of the predicted LW at initiation and termination of the trial.

${ }^{2} \mathrm{RT}=$ rumination time

${ }^{3}$ Remaining fraction $=\mathrm{OM}-$ (forage NDF + concentrate NDF $+\mathrm{CP}+$ starch + sugar $)$.

age NDF, sugar, starch, and the remaining fraction as suitable for analysis in step 2, where relationships between RT and dietary fractions were studied (Table 7). Concentrate NDF was excluded from the analysis due to multicollinearity, showing larger variation inflation factor than accepted. Cow, breed and parity were also significant in step 1 but not DIM and the CP fraction. In the final model of the multivariate analysis, where the intake variables were expressed in kilograms per day and in percentage of mpLW, RT decreased with increasing DIM and increasing intake of sugar and of the remaining fraction, whereas intakes of forage NDF and starch increased RT (Table 8). Breed and parity were not significant in step 2 and therefore were not included in the final model. For the 2 models, $\mathrm{R}^{2}$ decreased considerably when the random effects of cow(trial) and trial were removed, leaving the model to explain only $32 \%$ of the total variation in RT compared with $90 \%$ when the random effects of cow(trial) and trial were included in the model. Furthermore, for the 2 models, within-cow variation accounted for approximately $20 \%$ of the total variation, whereas between-cow variation accounted for approximately $48 \%$ of the total variation in RT, according to the variance components.

\section{Partial Correlation Between Dietary Fractions}

The partial Pearson correlation coefficient $(\mathrm{r})$ between forage NDF and RT was $0.28(P<0.001, \mathrm{n}=$ $1,254)$. A positive correlation $(\mathrm{r}=0.39 ; P<0.001, \mathrm{n}$ $=1,254$ ) was present between sugar and forage NDF intake, and the partial Pearson correlation between forage NDF and starch intake was negative $(\mathrm{r}=-0.51$; $P<0.001, \mathrm{n}=1,254)$. The partial Pearson correlation between the intake of the remaining fraction and forage NDF intake was positive $(\mathrm{r}=0.73 ; P<0.001, \mathrm{n}=$ $1,254)$.

\section{Relationship Between Rumination Time and Milk Production}

Rumination time was expressed in minutes per kilogram of DMI to account for the variation in RT related to individual DMI. Rumination time in minutes per kilogram of DMI was negatively related to milk yield and milk protein percentage but positively related to milk fat percentage (Table 9). Considering the random effects of cow(trial) and trial, the model was able to explain $81 \%$ of the variation in RT, but only $34 \%$ when 
Table 7. Parameter estimates and $P$-values from the PROC REG (step 1) analysis

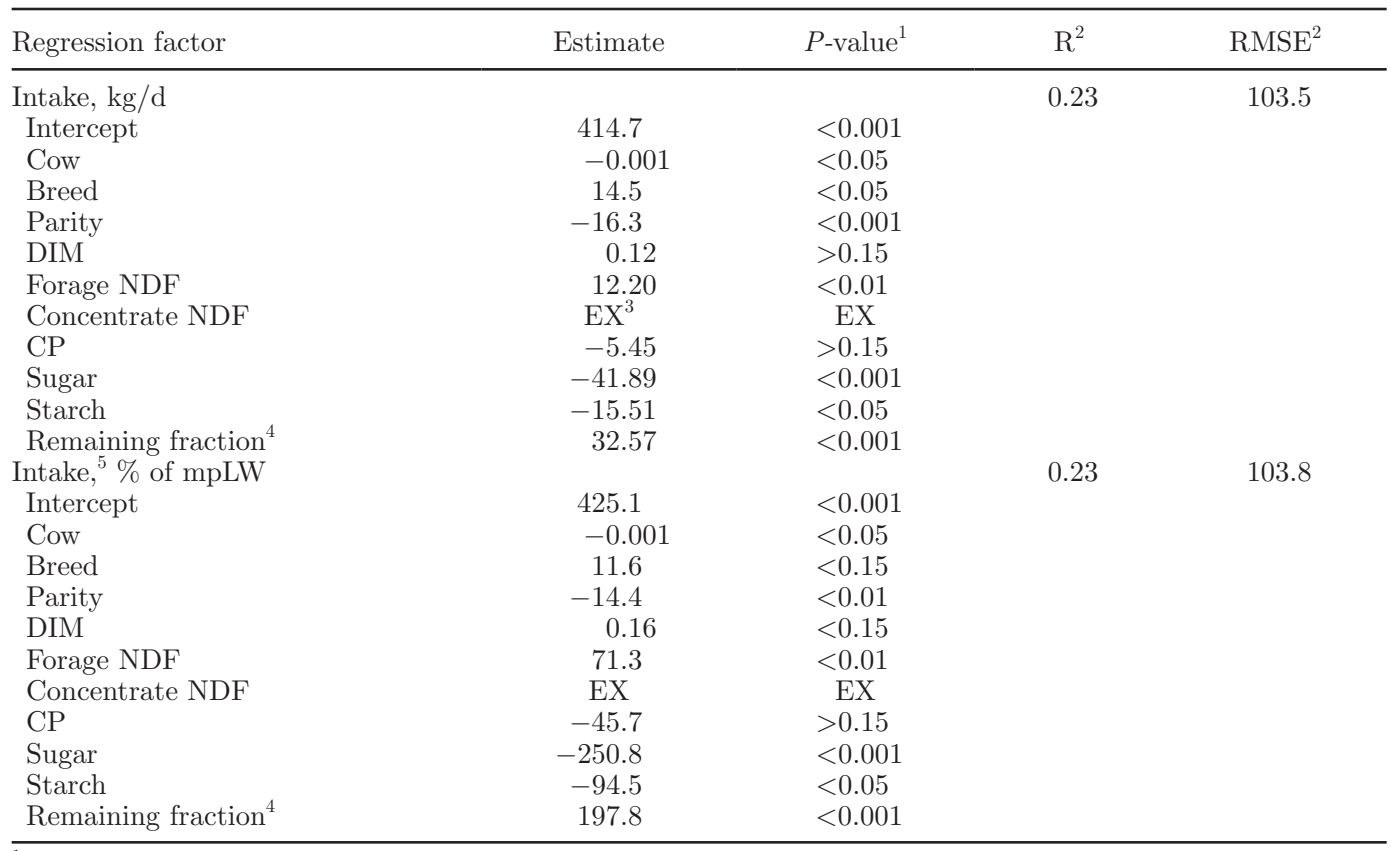

${ }^{1} P$-value for selection of dietary component expressed as intake or intake as a percentage of mpLW by step 1 analyses. Selection to enter step 2 in the analysis is based on a $P$-value $<0.15$ in step 1.

${ }^{2} \mathrm{RMSE}=$ root mean square error.

${ }^{3} \mathrm{EX}=$ excluded based on criteria for multicollinearity.

${ }^{4}$ Remaining fraction $=\mathrm{OM}-($ forage NDF + concentrate NDF $+\mathrm{CP}+$ starch + sugar $)$.

${ }^{5}$ Intake as percentage of mean predicted live weight $(\mathrm{mpLW})$ is the intake of one of the feed fractions divided by the mean of the individual mpLW at initiation and termination of the individual trials. For all trials, live weight was predicted based on a mixed model including information on breed, DIM, and parity.

Table 8. Relationships between rumination time $(\mathrm{min} / \mathrm{d})$ and dietary fractions, expressed as intake $(\mathrm{kg} / \mathrm{d})$ or as percentage of mean predicted live weight (mpLW)

\begin{tabular}{|c|c|c|c|c|c|c|}
\hline Item & Estimate & SEM & $P$-value & $\mathrm{R}_{\mathrm{RA}}^{2}$ & $\mathrm{R}^{2}{ }_{\mathrm{WRA}}^{2}$ & $\mathrm{RMSE}^{3}$ \\
\hline Intake, $\mathrm{kg}$ of $\mathrm{DM} / \mathrm{d}$ & & & & 0.90 & 0.32 & 55.87 \\
\hline Intercept & 489.08 & 45.47 & $<0.01$ & & & \\
\hline DIM & -0.41 & 0.10 & $<0.001$ & & & \\
\hline Forage NDF & 22.07 & 3.04 & $<0.001$ & & & \\
\hline Sugar & -47.29 & 9.74 & $<0.001$ & & & \\
\hline Starch & 13.02 & 5.20 & $<0.05$ & & & \\
\hline Remaining fraction ${ }^{4}$ & -22.49 & 6.08 & $<0.001$ & & & \\
\hline Intake, ${ }^{5} \%$ of mpLW & & & & 0.89 & 0.31 & 55.94 \\
\hline Intercept & 487.0 & 45.83 & $<0.01$ & & & \\
\hline DIM & -0.40 & 0.10 & $<0.001$ & & & \\
\hline Forage NDF & 136.13 & 18.87 & $<0.001$ & & & \\
\hline Sugar & -282.41 & 58.90 & $<0.001$ & & & \\
\hline Starch & 77.80 & 32.06 & $<0.05$ & & & \\
\hline Remaining fraction ${ }^{4}$ & -137.03 & 37.65 & $<0.001$ & & & \\
\hline
\end{tabular}

${ }^{1} \mathrm{R}_{\mathrm{RA}}^{2}=\mathrm{R}^{2}$ considering the random effects of cow(trial) and trial.

${ }^{2} \mathrm{R}_{\text {WRA }}^{2}=\mathrm{R}^{2}$ not considering the random effects of cow(trial) and trial.

${ }^{3} \mathrm{RMSE}=$ root mean square error.

${ }^{4}$ Remaining fraction $=\mathrm{OM}-($ forage NDF + concentrate NDF $+\mathrm{CP}+$ starch + sugar $)$.

${ }^{5}$ Intake as percentage of mpLW is the intake of one of the feed fractions divided by the mean of the individual predicted LW at initiation and termination of the individual trials. For all trials, LW was predicted based on a mixed model including information on breed, DIM and parity group. 
Table 9. Relationships between rumination time ( $\mathrm{min} / \mathrm{kg}$ of DMI) and milk yield, fat, and protein percentages in milk

\begin{tabular}{lccccc}
\hline Item & Estimate & SEM & $P$-value & $\mathrm{R}_{\text {RA }}^{2}$ & $\mathrm{R}_{\text {WRA }}^{2}$ \\
\hline & 32.42 & 3.45 & $<0.001$ & 0.81 & 0.34 \\
Intercept & -0.27 & 0.03 & $<0.001$ & & \\
Milk yield, $\mathrm{kg} / \mathrm{d}$ & 0.82 & 0.32 & $<0.05$ & & \\
Fat, \% & -1.45 & 0.55 & $<0.01$ & & \\
Protein, $\%$ & \multicolumn{3}{l}{} & \\
${ }^{1} \mathrm{R}_{\text {RA }}^{2}=\mathrm{R}^{2}$ considering the random effects of cow(trial) and trial. \\
${ }^{2} \mathrm{R}_{\text {WRA }}^{2}=\mathrm{R}^{2}$ not considering the random effects of cow(trial) and trial.
\end{tabular}

cow(trial) and trial were excluded from the model. Cow characteristics described as parity, breed, and DIM, along with mpLW, lactose, and SCC were not significantly related to RT per DMI.

\section{DISCUSSION}

The RMS has been developed to indicate occurrence of heat or disease in individual dairy cows, based on sudden drops in RT. Daily RT is mainly driven by the intake of forage NDF (Mertens, 1997; Nørgaard et al., 2011) and, consequently, the recorded RT values recorded by RMS can potentially serve as an indirect method of recording intake of forage NDF or intake of TMR diets at minimal sorting behavior. However, Clément et al. (2014) observed no correlation between RT and daily intake of TMR DM fed to lactating dairy cows. Likewise, Schirmann et al. (2012) found no relationship between ruminating time and DMI across dry cows, but a correlation within cows. Therefore, this study was performed with the objective to examine the relationship between intake of different dietary fractions and milk production and daily RT recorded by the RMS, in Swedish Red and Holstein cows. Furthermore, the objective was to examine the potential variation in RT within and between cows when accounting for the variation in the intake of the dietary fractions.

The 27 diets used in this analysis included large variations in dietary contents of NDF from forage, CP, sugar, starch, and residual OM, and therefore provided a basis for the regression analysis. The results showed that increased forage NDF intake in kilograms per day and as a percentage of mpLW significantly increased RT by $22 \mathrm{~min} / \mathrm{kg}$ of forage NDF intake or by $136 \mathrm{~min} /$ forage NDF intake as a percentage of mpLW. However, the marginal effect of 22 min RT per $\mathrm{kg}$ of NDF intake is much lower than $109 \mathrm{~min}$ per $\mathrm{kg}$ of forage NDF by a meta-analysis of 79 different dietary treatments (Nørgaard et al., 2010). Kargar et al. (2010) and Yang et al. (2001) reported 88 to $133 \mathrm{~min}$ RT per $\mathrm{kg}$ of forage NDF intake when feeding diets similar to our 27 different dietary treatments. The intake of the different dietary fractions is estimated from the automatically recorded weight of the residual TMR in the feeder. Kononoff et al. (2003) and Maulfair et al. (2010) have reported sorting behavior against forage NDF in cows fed TMR depending on forage:concentrate ratio. Such behavior might have compromised the predicted intake of the different dietary fractions by the individual cows. In addition, some of the cows displayed a low RT, and even though unexpected low recordings of RT have been excluded from the data, some of the remaining low recordings of RT might have decreased the relationship between forage NDF and RT in the analysis. The ability of the RMS to record RT precisely has been confirmed by Schirmann et al. (2009) and Byskov et al. (2014), reporting correlations between RT, recorded either by visual observation or by chewing halter, and the RMS of $\mathrm{r} \geq 0.91$ at the $2 \mathrm{~h}$ level. Even so, some deviations between the true RT value, represented by visually observed or recorded RT, and RT recorded by the RMS, were found. Accordingly, in this study some of the recorded RT values might be underestimated, potentially explaining the lower relationship between forage NDF intake and RT compared with the abovementioned studies. The potential error in recording feed intake in experimental herds might also contribute to this. The relationship between RT and forage NDF was not greater when expressed as forage NDF intake as a percentage of mpLW, and therefore the potential effect of size could not account for some of the variation. For the grass silages used in these 3 trials, in vitro $\mathrm{OM}$ digestibility was only determined for the grass silages used in trial 3. This was highly digestible, with an in vitro OM digestibility of $917 \mathrm{~g} / \mathrm{kg}$ of $\mathrm{OM}$ (Nadeau et al., 2012). However, for the grass silage used in trial 3, the NDF content was somewhat lower (403-415 g/ kg of DM) compared with the NDF content of the grass silages used in trials 1 and $2(452-602 \mathrm{~g} / \mathrm{kg}$ of DM). As RT is stimulated by the intake of forage NDF (Mertens, 1997), the lower mean RT for cows in trial 3, could be explained by the high digestibility and low NDF content of grass silage in agreement with Adin et al. (2009), who observed a decreased RT in dairy cows by 
reducing the proportion of forage NDF in TMR diets. This might also have affected the estimated relationship between RT and forage NDF by decreasing the parameter estimate. The partial Pearson correlation coefficient between forage NDF and RT was positive, showing a somewhat lower correlation compared with Yang and Beauchemin $(2007,2009)$, who found correlations between intake of forage NDF and RT of 0.41 and 0.44 . Because all forage feed in the 3 trials was chopped to approximately $15 \mathrm{~mm}$ and the concentrates were generally fed as pelleted feed, the peNDF values were small. Yang and Beauchemin (2009) found an increased RT per kilogram of peNDF and an increased correlation between RT and intake of forage NDF by feeding an increased proportion of forage NDF, which shows that variations in forage type and proportion of forage NDF in TMR diets may affect RT per kilogram of NDF.

The multivariate analysis showed a negative relationship between RT and intakes of sugar and the remaining fraction. When studying the partial Pearson correlation between the intakes of forage NDF, as the expected main driver for RT, and the remaining dietary fractions, a positive correlation was present between sugar and forage NDF intake. However, this is contradictory to the negative relationship between sugar and RT. Nonetheless, an increase in concentrate proportion and thereby an increase in sugar content, might explain the negative relation between sugar intake and RT, especially for trial 1 with varying forage proportions. The effect of increasing concentrate proportion on RT was confirmed by Yang and Beauchemin (2009). In contrast to Yang and Beauchemin (2009), an increased starch intake due to a higher dietary concentrate proportion and inclusion of maize silage appeared to be related to greater RT in this study. The partial Pearson correlation between forage NDF and starch intake was negative, which did not explain the unexpected positive relation between RT and starch intake. However, the marginal increase of RT of $13 \mathrm{~min} / \mathrm{kg}$ of starch intake results in a relatively small increase in RT due to the lower intake of starch compared with forage NDF. Furthermore, the rumen digestibility of starch can vary because starch from corn silage is degraded more slowly and contains more bypass starch compared with starch from grain (McDonald et al., 2002; Weisbjerg et al., 2003). Use of corn silage in 2 of the 3 trials within this study might explain the positive relationship between starch intake and RT due to the potential improvement of the rumen environment feeding more bypass starch. The intake of the remaining fraction was positively related to RT. The partial Pearson correlation between the intake of the remaining fraction and forage NDF intake was positive. This relation again is contradictory to the negative relation between $\mathrm{RT}$ and the remaining fraction intake, even though the remaining fraction in itself is not expected to stimulate RT. The intakes of concentrate NDF and $\mathrm{CP}$ were not included in the final multivariate model due to insignificant effects in step 1 of the analysis. For concentrate NDF, this absence of a significant effect on RT might be explained by the fact that all concentrates used within these trials were fed as pelleted feed, which was not expected to affect RT significantly. For CP intake, the absence of a significant effect on RT might be explained by the fact that, in all trials, CP was fed in amounts that did not expect to have a detrimental effect on microbial growth and maintenance, which otherwise might have affected RT negatively by reducing fiber degradation (Allen, 2000).

The proportion of the variation in RT, which could be explained by the variation in intakes of the different dietary fractions, drastically decreased from 90 to $32 \%$ when the random effects of cow(trial) and trial were excluded from the model. This reduction could be explained by the variation between cows of $48 \%$ found in this study. The variation in RT between cows, which was not accounted for by variations in the intake of the dietary fractions, is presumably related to natural variation. Dado and Allen (1994) found that the coefficient of variation in RT was $16 \%$ for 12 primiparous and multiparous cows at a similar stage of lactation fed the same TMR diet. In a study recording RT with the RMS of 50 Holstein dairy cows fed 2 different TMR diets differing in peNDF content, the SEM for RT was 13 min (Adin et al., 2009), whereas the SEM for RT recorded in these 3 trials was about $17 \mathrm{~min}$ (results not shown). The variation between cows in this study is somewhat greater, however, still within a close range of the previously mentioned studies. This confirms that the range of variation between cows found in this study is within the range of what can be expected when RT is recorded by the RMS under field conditions.

The precision of the prediction of mpLW without information on cow(trial) and trial was less accurate, which was the case for prediction of mpLW for cows in trial 1. However, as mpLW states the mean of the predicted LW at initiation and termination of the trial, in contrast to a precise daily weight change, mpLW is expected to be a credible parameter for the purpose for which it is used. The majority $(75 \%)$ of the recordings from which the model was built were performed on cows in second lactation. Consequently, the variation in LW was greater within this group, which might account for the unexpected greater LW for second parity cows compared with older cows with a higher parity.

Milk yield was found to decrease with increasing RT per kilogram of DMI, which is in agreement with results by Dado and Allen (1994), who found a nega- 
tive correlation between milk yield and RT in minutes per kilogram of DMI of $r=-0.68$. Milk fat percentage increased with increasing $\mathrm{RT}$ in minutes per kilogram of DMI, which might be related to a higher forage percentage. Similar results were found by Mertens (1997) where milk fat percentage increased curve linearly with an increasing peNDF content in DM. Milk protein yield, on the other hand, decreased with increasing RT per kilogram of DMI, which is similar to results by others (Moorby et al., 2006; Yang and Beauchemin, 2007, 2009).

In this study, only $32 \%$ of the variation in RT could be accounted for by variations in the dietary fractions. Even though, RT recorded by the RMS seems to at least indicate the forage:concentrate ratio at group level, large individual variations in RT between cows, challenges the use of the RT recorded by the RMS for prediction of feed intake by individual cows, but the recorded RT values by RMS appear to provide information on the relative intake of individual cows over time.

\section{CONCLUSIONS}

Approximately $32 \%$ of the variation in RT was related to the variation in intakes of forage NDF, starch, sugar and the remaining fraction in individual cows and DIM, whereas $48 \%$ of the total variation in RT was found between cows. The daily intakes of forage $\mathrm{NDF}$ and starch were positively related to RT, whereas intakes of sugar and the remaining fraction were negatively related to RT. The mean RT per kilogram of DMI was negatively related to daily milk yield and milk protein percentage, but positively related to milk fat percentage. The relationship between intake of forage $\mathrm{NDF}$ and RT accounted for a lower proportion of the variation in recorded RT by RMS than expected.

\section{ACKNOWLEDGMENTS}

Bo Markussen, University of Copenhagen (Denmark), is acknowledged for his statistical advice. ADDCON Europe GmbH (Germany), Agroväst (Sweden), VLFoundation (Sweden), Lantmännen (Sweden), Agrifirm Innovation Center (the Netherlands), and Swedish University of Agricultural Sciences (Skara, Sweden) are acknowledged for their funding of trial 3, and Agrifirm Innovation Center and Lantmännen are acknowledged for their funding of trials 1 and 2 .

\section{REFERENCES}

Adin, G., R. Solomon, M. Nikbachat, A. Zenou, E. Yosef, A. Brosh, A. Shabtay, S. J. Mabjeesh, I. Halachmi, and J. Miron. 2009. Effect of feeding cows in early lactation with diets differing in roughage neutral detergent fiber content on intake behavior, rumination and milk production. J. Dairy Sci. 92:3364-3373.

Allen, M. S. 2000. Effects of diet on short-term regulation of feed intake by lactating dairy cattle. J. Dairy Sci. 83:1598-1624.

Aman, P., and K. Hesselman. 1984. Analysis of starch and other main components of cereal grain. Swed. J. Agric. Res. 14:135-139.

Bae, D. H., J. G. Welch, and B. E. Gilman. 1983. Mastication and rumination in relation to body size of cattle. J. Dairy Sci. 66:21372141.

Beauchemin, K. A., and L. M. Rode. 1994. Compressed baled alfalfa hay for primiparous and multiparous dairy cows. J. Dairy Sci. 77:1003-1012.

Byskov, M. V., A. K. S. Schulze, M. R. Weisbjerg, B. Markussen, and P. Nørgaard. 2014. Recording rumination time by a rumination monitoring system in Jersey heifers fed grass/clover silage and hay at three feeding levels. J. Anim. Sci. 92:1110-1118.

Clément, P., R. Guatteo, L. Delaby, B. Rouillé, A. Chanvallon, J. M. Philipot, and N. Bareille. 2014. Short communication: Added value of rumination time for the prediction of dry matter intake in lactating cows. J. Dairy Sci. 97:6531-6535.

Dado, R. G., and M. S. Allen. 1994. Variation in and relationships among feeding, chewing, and drinking variables for lactating dairy cows. J. Dairy Sci. 77:132-144

Kargar, S., M. Khorvash, G. R. Ghorbani, M. Alikhani, and W. Z. Yang. 2010. Short communication: Effects of dietary fat supplements and forage:concentrate ratio on feed intake, feeding, and chewing behavior of Holstein dairy cows. J. Dairy Sci. 93:42974301

Kononoff, P. J., A. J. Heinrichs, and H. A. Lehman. 2003. The effect of corn silage particle size on eating behavior, chewing activities, and rumen fermentation in lactating dairy cows. J. Dairy Sci 86:3343-3353

Krause, K. M., D. K. Combs, and K. A. Beauchemin. 2002. Effects of forage particle size and grain fermentability in midlactation cows. II. Ruminal $\mathrm{pH}$ and chewing activity. J. Dairy Sci. 85:1947-1957.

Lindgren, E. 1979. Vallfodrets näringsvärde bestämt in vivo och med olika laboratoriemetoder. Pages 1-66 in Rapport 45. Dept. Anim. Nutr. Management, Swed. Univ. Agric. Sci., Uppsala, Sweden. (in Swedish with English summary).

Lindgren, E. 1983. Nykalibrering av VOS-metoden for bestamning av energivarde hos vallfoder. Dept. of Animal Nutr. and Management, Swedish Univ. Agric. Sci., Uppsala, Sweden. (in Swedish)

Lindgren, E., M. Murphy, and T. Andersson. 2001. Värdering av foder. Lantmännen Foderutveckling AB, Nötfor. Almqvist \& Wiksell, Uppsala, Sweden. (in Swedish)

Maulfair, D. D., G. I. Zanton, M. Fustini, and J. Heinrichs. 2010. Effect of feed sorting on chewing behavior, production, and rumen fermentation in lactating dairy cows. J. Dairy Sci. 93:4791-4803.

McDonald, P., R. A. Edwards, and J. F. D. Greenhalgh. 2002. Animal Nutrition. 6th ed. Longman, London, UK.

Mertens, D. R. 1997. Creating a system for meeting the requirements of dairy cows. J. Dairy Sci. 80:1463-1481.

Moorby, J. M., R. J. Dewhurst, R. T. Evans, and J. L. Danelón. 2006. Effects of dairy cow diet forage proportion on duodenal nutrient supply and urinary purine derivative excretion. J. Dairy Sci 89:3552-3562.

Nadeau, E., W. Richardt, M. Murphy, and H. Auerbach. 2012. Protein quality dynamics during wilting and preservation of grass-legume forage. Pages $67-57$ in Proceedings of the XVI International Silage Conference, Hämeenlinna. K. Kuoppala, M. Rinne, and A. Vanhatalo, ed. MTT Agrifood Research/University of Helsinki, Finland.

Nørgaard, P., E. Nadeau, and A. T. Randby. 2010. A new Nordic evaluation system for diets fed to dairy cows: A meta analysis. Pages 112-120 in Modelling Nutrient Digestion and Utilisation in Farm Animals. D. Sauvant, J. Van Milgen, P. Faverdin, and N. Friggens, ed. Wageningen Academic Publishers, Wageningen, the Netherlands.

Nørgaard, P., E. Nadeau, A. T. Randby, and H. Volden. 2011. Chewing index system for predicting physical structure of the diet. Pages 127-132 in NorFor-The Nordic feed evaluation system. EAAP 
publication no. 130. 1st ed. H. Volden, ed. Wageningen Academic Publishers, Wageningen, the Netherlands.

Schirmann, K., N. Chapinal, D. M. Weary, W. Heuwieser, and M. A. G. von Keyserlingk. 2012. Rumination and its relationship to feeding and lying behavior in Holstein dairy cows. J. Dairy Sci. 95:3212-3217.

Schirmann, K., M. A. G. von Keyserlingk, D. M. Weary, D. M. Veira, and W. Heuwieser. 2009. Technical note: Validation of a system monitoring rumination in dairy cows. J. Dairy Sci. 92:6052-6055.

Sjaunja, L. O., L. Baevre, L. Junkkarinen, J. Pedersen, and J. Setälä. 1990. A Nordic proposal for an energy corrected milk (ECM) formula. Pages 156-157 in Proc. 2nd Session of International Committee for Recording and Productivity of Milk Animal, Paris, France. Wageningen Academic Publishers, Wageningen, the Netherlands.

Soriani, N., E. Trevisi, and L. Calamari. 2012. Relationships between rumination time, metabolic conditions, and health status in dairy cows during the transition period. J. Anim. Sci. 90:4544-4554.

Sterk, A., B. E. Johansson, H. Z. H. Taweel, M. Murphy, A. M. van Vuuren, W. H. Hendriks, and J. Dijkstra. 2011. Effects of forage type, forage to concentrate ratio, and crushed linseed supplementation on milk fatty acid profile in lactating dairy cows. J. Dairy Sci. 94:6078-6091.

Teimouri Yansari, A., R. Valizadeh, A. Naserian, D. A. Christensen, P. Yu, and F. Eftekhari Shahroodi. 2004. Effects of alfalfa particle size and specific gravity on chewing activity, digestibility and performance of Holstein dairy cows. J. Dairy Sci. 87:3912-3924.
Van Soest, P. J., J. B. Robertson, and B. A. Lewis. 1991. Methods for dietary fiber, neutral detergent fiber, and nonstarch polysaccharides in relation to animal nutrition. J. Dairy Sci. 74:3583-3597.

van Vuuren, A. M., C. J. Van Der Koelen, H. Valk, and H. De Visser. 1993. Effects of partial replacement of Ryegrass by low protein feeds on rumen fermentation and nitrogen loss by dairy cows. J. Dairy Sci. 76:2982-2993.

von Lengerken, J., and K. Zimmermann. 1991. Handbuch Futtermittelprüfung. Deutscher Landwirtschaftsverlag, Berlin, Germany.

Weisbjerg, M. R., P. Lund, and T. Hvelplund. 2003. Kulhydratomsætningen i mave-tarmkanalen. Pages 238-280 in Kvægets ernæring og fysiologi. Bind 1-Næringsstofomsætning og fodervurdering. DJF rap. Husdyrbrug nr. 53. T. Hvelplund and P. Nørgaard, ed. Ministeriet for Fødevarer, Landbrug og Fiskeri, Danmarks JordbrugsForskning. DigiSource, Viborg, Denmark.

Yang, W. Z., and K. A. Beauchemin. 2007. Altering physically effective fiber intake through forage proportion and particle length Chewing and ruminal pH. J. Dairy Sci. 90:2826-2838.

Yang, W. Z., and K. A. Beauchemin. 2009. Increasing physically effective fiber content of dairy diets through forage proportion versus forage chop length: Chewing and ruminal pH. J. Dairy Sci. 92:1603-1615

Yang, W. Z., K. A. Beauchemin, and L. M. Rode. 2001. Barley processing, forage:concentrate, and forage length effects on chewing and digesta passage in lactating cows. J. Dairy Sci. 84:2709-2720. 